\title{
Sistema de Saúde Móvel
}

Mobile Health System

NASCIMENTO, Beatriz A. de Souza; Graduanda; Universidade da Região de Joinville - UNIVILLE bia28andry@gmail.com

JAHN, Ana Cláudia; Graduanda; Universidade da Região de Joinville - UNIVILLE anacjahn@hotmail.com

VELA, João Carlos; Mestre; Universidade da Região de Joinville - UNIVILLE joao.vela1@gmail.com

\section{Resumo}

O Sistema Público de Saúde da cidade de Joinville encontra-se com dificuldades, tais como: unidades de saúde insuficientes, superlotações, vagas limitadas e infraestrutura precária. Este artigo tem como objetivo apresentar um estudo teórico preliminar, que guiará futuramente um projeto de conclusão de curso, cujo tema será o desenvolvimento de um ambiente itinerante de saúde pelo viés do Design de Interiores, que possam auxiliar na redução das dificuldades apresentadas na cidade. Como resultado, este trabalho aponta a possibilidade do desenvolvimento de unidades móveis de saúde, no qual, o design de interiores norteará a elaboração de um ambiente eficiente, funcional e agradável.

Palavras Chave: SUS; Design de Interiores; Móvel.

\section{Abstract}

The Public Health System of the city of Joinville has difficulties, such as: insufficient health units, overcrowding, limited vacancies and poor infrastructure. This article aims to present a preliminary theoretical study that will guide in the future a project for the conclusion of a course, the theme of which will be the development of an itinerant health environment through the bias of Interior Design, which may help to reduce the difficulties presented in the city. As a result, this work points to the possibility of developing mobile health units, in which interior design will guide the elaboration of an efficient, functional and pleasant environment

Keywords: SUS; Interior Design; Mobile. 


\section{Introdução}

Apesar da contribuição do Sistema Único de Saúde - SUS, para que a população brasileira tenha acesso a atendimentos médicos e consequentemente melhore a sua qualidade de vida, é um sistema que ainda necessita de adequações e de expansão nos seus serviços. Neste sentido, o desenvolvimento de uma nova proposta de ambiente destinado para atendimentos do SUS, que proporcione levar os serviços de saúde até a população mais afastada dos estabelecimentos existentes, torna-se relevante.

Para tal, este trabalho buscará entender melhor o histórico do SUS, sua situação atual no país e a sua atuação em Santa Catarina, mais precisamente na cidade de Joinville, com o propósito de nortear o desenvolvimento de um projeto de conclusão de curso (TCC), que será focado na elaboração prática de tais espaços.

O propósito desta investigação é levantar os principais pontos de defasagem dos serviços públicos de saúde, para apontar a possibilidade de desenvolvimento de um modelo de unidade itinerante que leve atendimento médico à população, podendo ser adaptado e utilizado para diversas especialidades médicas (clínica geral, obstetrícia, ginecologia, etc.), deste modo cada unidade circulará independentemente umas das outras pela cidade.

Será apresentado, portanto, os apontamentos iniciais para o desenvolvimento de um sistema de atendimento móvel, bem como o ambiente interno dos postos de atendimento, que se baseará nas premissas do design de interiores, uma vez que este apresenta-se como um elemento capaz de criar ambientes que otimize e facilite as atividades realizadas, proporcionando conforto e segurança aos usuários do espaço, de forma funcional e acessível.

\section{Sistema Único de Saúde - SUS}

Anteriormente a implementação do SUS, o sistema público de saúde era associado a Previdência Social, ou seja, era restrito a parcela da população vinculada formalmente ao mercado de trabalho, os demais indivíduos que não possuíam este vínculo ou que não dispunham de recursos financeiros, eram atendidos por poucas instituições públicas ou de caráter filantrópico (SOUZA, 2002).

Em 1988, graças ao Movimento da Reforma Sanitária, foi instituído pela Constituição Federal (CF) o Sistema Único de Saúde, com o princípio de que a saúde era um direito dos cidadãos e um dever do Estado, entretanto, só foi realmente consolidado no ano de 1990, com a aprovação da Lei Orgânica da Saúde (Lei 8.080/90) que determina as atribuições e organização do SUS (PAIM et.al., 2011; SANTOS et. al., 2013).

Com o propósito de propor um novo ambiente de atendimento de saúde que esteja adequado às necessidades da população, será apresentado na sequência, a atual situação do sistema público de saúde brasileiro, apontando algumas dificuldades que o SUS enfrenta.

\subsection{Cenário Atual do Sistema Único de Saúde Brasileiro}

O sistema de saúde público brasileiro é uma das maiores reclamações da população, possuindo como principais problemas a falta de gestão adequada e o baixo financiamento, segundo levantamentos, o Brasil dedica apenas 4,66\% do Produto Interno Bruto (PIB) no setor da saúde, o que o coloca em $11^{\circ}$ lugar entre os países da América no ranking de investimento 
na saúde (RIOS, web, 2015).

Os indivíduos que necessitam de atendimento se deparam com tempo de espera excessivo para algumas consultas ou procedimentos, chegando a ultrapassar 6 meses de espera. Outro problema que enfrentam é a superlotação de hospitais, segundo dados do Tribunal de Contas da União (TCU), cerca de 64\% dos hospitais estão sempre lotados e apenas 6\% não utilizam sua capacidade máxima. Além destes fatores há problemas de falta de médicos no interior dos estados, estrutura de atendimento defasada e falta de capacitação de profissionais (ROSSI, web, 2015; MV, web, 2016).

Apesar de algumas defasagens no atendimento da população, o SUS possui alguns programas que atingem um nível satisfatório de cobertura, tais como o programa de imunização que consegue atingir $100 \%$ da população desde o ano 2000, e o programa de transplante, no qual o serviço público de saúde realiza 95\% dos procedimentos (MV, web, 2016).

Os diferenciais destes programas, são o fato de serem totalmente gratuitos e chegarem ao alcance da população por meio de campanhas e iniciativas que levam unidades ou profissionais ao encontro dos pacientes. Com isso, estas características deverão ser consideradas na elaboração do projeto proposto, uma vez que mesmo com as dificuldades que o SUS enfrenta, estes programas conseguem funcionar com eficácia, alcançando boa parte da população.

Deste modo, apesar dos problemas apresentados na área da saúde, questiona-se a possibilidade de otimização dos serviços já oferecidos pelo SUS, por meio da utilização das diretrizes do design de interiores na elaboração de novos espaços que abordem de maneira diferenciada o atendimento à população, facilitando o acesso a saúde.

\section{Sistema de Saúde em Santa Catarina}

A atual situação do SUS em Santa Catarina não é muito diferente da conjuntura nacional, demonstrado anteriormente. Segundo Moacir Pereira (web, 2016) o ano de 2016, foi marcado por crise no sistema público de saúde do estado, decorrente da crise econômica brasileira e do congelamento das tabelas do SUS, levando alguns hospitais comunitários e filantrópicos a falência.

Os usuários da rede pública de saúde, do estado de Santa Catarina, enfrentam diversos problemas para conseguirem atendimento adequado, que vão desde a falta de materiais, de aparelhos médicos e de recursos financeiros, déficit de funcionários, longas filas de espera e superlotação (G1, web, 2016).

O jornalista Renato Igor em uma matéria do Bom Dia Santa Catarina, apresentou que de 1919 leitos públicos disponíveis no estado ocorreu um declínio para 1897 leitos no ano de 2016, e atualmente a saúde pública conta somente com 10.400 funcionários. (G1, web, 2016).

Este panorama demonstra a necessidade de se buscar meios de otimizar os serviços de atendimento à população, de modo a amenizar os problemas existentes, para que isto seja possível será apresentado a situação do SUS na maior cidade do estado - Joinville, que será utilizada como referência para o desenvolvimento da proposta deste artigo. 


\subsection{Sistema de Saúde em Joinville}

Joinville é considerada a maior cidade do estado, tanto em extensão territorial quanto em número populacional, possuindo aproximadamente 570 mil habitantes e $1.126 \mathrm{Km}^{2}$, segundo dados do IBGE, divulgados no ano de 2016 (IBGE, 2016).

Segundo a Secretaria de Planejamento Urbano e Desenvolvimento Sustentável (2017) a cidade de Joinville conta principalmente com os seguintes serviços de saúde, disponibilizados pelo SUS: 55 UBS - Unidades Básicas de Saúde; 19 Serviços Ambulatoriais; 32 Postos de Coleta de Exames; 31 Centros Especializados; 5 Hospitais; 3 PAs - Pronto Atendimento; 5 Prontos-Socorros Gerais e 65 Farmácias.

Sendo as três principais unidades de saúde o UBS - responsável pelos atendimentos básicos, onde são realizados exames, consultas e acompanhamentos, além de entrega de remédios e aplicação de vacinas; PAs - unidade de urgência e emergência, responsável por atendimentos de média e alta complexidade, que funciona 24 horas por dia, mas não possui leitos de internação ou centros cirúrgicos; Hospital - unidade que atende casos de alta complexidade e emergência, possui mais recursos tecnológicos de intervenção, onde são realizados procedimentos mais invasivos e que pode atribuir risco de morte (ALVES, web, 2014).

Apesar da quantidade considerável de serviços disponíveis na região de Joinville, o sistema público de saúde ainda se apresenta insuficiente. E um dos problemas preocupantes na cidade, são as longas filas de espera do SUS, que de acordo com o jornal Notícias do Dia somavam 109 mil pessoas, no ano de 2014, que aguardavam desde realização de consultas e exames, até cirurgias de grande porte, que segundo a lista da Secretaria Municipal de Saúde, chega a um tempo médio de dois anos de espera (MIRA, web, 2014)

A maior cidade do estado, sofre também com a superlotação de seus Hospitais, PAs e Prontos Socorros. No ano de 2016, foi registrado uma ocupação de 140\% no Hospital São José, o que é uma situação inapropriada, no qual, os pacientes são atendidos em leitos improvisados nos corredores do hospital, isto se conseguirem algum auxílio médico (G1, web, 2016).

A falta de medicamentos é outro problema latente nos setores da saúde pública, impedindo a realização adequada dos tratamentos. Uma reportagem do Jornal do Almoço relatou a necessidade da suspensão de tratamentos intensivos de saúde, no final de 2016 no Hospital São José, devido a esta defasagem (G1, web, 2016).

Diante de todos esses problemas que o SUS enfrenta na cidade, principalmente as superlotações, percebe-se que a quantidade de Pronto Atendimento em Joinville, está muito abaixo do ideal para uma extensão territorial tão grande, uma vez que são apenas 3 PAs 24h, distribuídos na região Sul, Leste e Norte da cidade, conforme apresentado na figura 1, no qual a orientação do mapa necessitou ser alterado para uma melhor visualização e foi acrescentado uma rosa dos ventos para localização. 


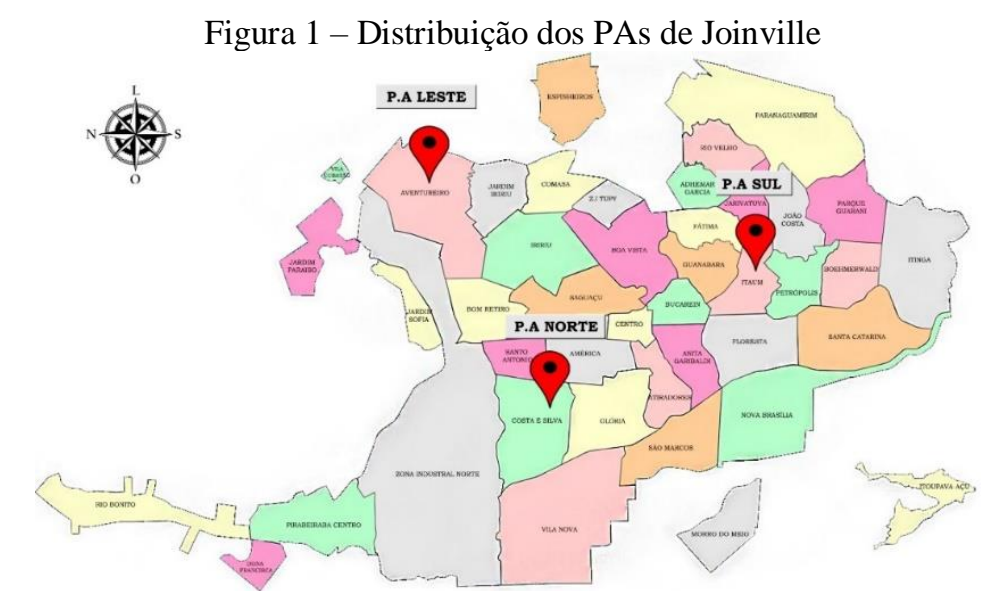

Fonte: mapasblog.blogspot.com.br (2011), modificado pelo autor (2017)

Ao considerar uma distribuição igualitária de atendimento, o que está longe da realidade, cada PA deveria ser responsável por atender aproximadamente 190 mil pessoas, entretanto esta distribuição é desigual, de modo a um PA possuir maior demanda que outro. Contudo o estudo deste mapa procura demonstrar que as pessoas que moram em bairros mais afastados dos PAs, enfrentam dificuldade e demora no deslocamento até os estabelecimentos, e quando chegam se deparam com tempo de espera excessivo devido a superlotação, falta de profissionais e de infraestrutura adequada, além de carência de equipamentos e remédios.

Já em relação as Unidades Básicas de Saúde, que consistem no primeiro estabelecimento médico que os pacientes procuram, apesar de serem 55 postos, mostram-se insuficientes para suprir a demanda da cidade, na figura 2 é possível analisar a distribuição destas unidades, que se apresentam desiguais.

Figura 2 - Distribuição das Unidade Básicas de Saúde de Joinville

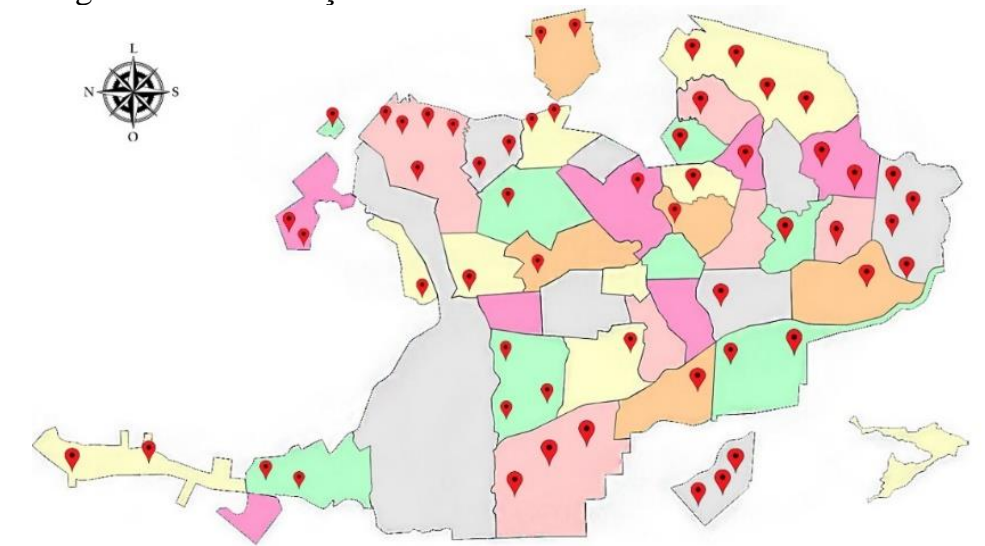

Fonte: mapasblog.blogspot.com.br (2011), modificado pelo autor (2017)

Cada UBS, se considerar uma distribuição igualitária, está responsável por atender aproximadamente 10.364 mil pessoas, mas assim como os PAs, algumas unidades possuem mais demandas que outras, no mapa apresentado é possível observar que alguns bairros da cidade não possuem nenhuma unidade, portanto os indivíduos necessitam se deslocar consideravelmente para conseguir atendimento. Uma situação frequente nas unidades de saúde, é a necessidade da população de chegar cedo nos postos, até mesmo antes do horário de 
funcionamento e ficar esperando na parte de fora dos estabelecimentos, para conseguir vagas para serem atendidos. Isto ocorre, uma vez que há uma demanda muito grande para cada unidade, como relatado anteriormente, e além disto cada médico do posto de saúde, possui uma quantidade limitada de atendimentos por dia, o que intensifica a ocorrência filas para consultas e o mesmo ocorre para agendar exames.

Observa-se, portanto, que as Unidades Básicas de Saúde possuem aproximadamente 18 vezes mais unidades que os Prontos Atendimentos, entretanto em alguns casos, os usuários que buscam as UBS são encaminhados justamente para um atendimento mais especializado junto aos PAs ou Hospitais. Neste sentido, questiona-se a possibilidade de unidades intermediárias que possuíssem a capacidade de ir ao encontro da população, uma vez que nos serviços bemsucedidos atualmente no SUS, percebe-se que o fato de levar o atendimento até a população apresenta-se como seus diferenciais.

Ao pensar na atual situação financeira do sistema público de saúde, e seus problemas de financiamento, um modal de atendimento que apresente um custo inferior as construções tradicionais dos PAs e UBS, além de um tempo reduzido de construção mostra-se relevante, portanto, um atendimento móvel que aproxime a população da assistência médica seria uma opção.

O design de interiores apresenta-se como o componente principal desta proposta, uma vez que será capaz de criar ambientes que otimize e facilite as atividades realizadas, proporcione conforto e segurança aos usuários do espaço, além de considerar aspectos de acessibilidade e sustentabilidade.

\section{Projeto de Interiores}

Com as circunstâncias apresentadas do sistema público de saúde da cidade de Joinville, e a necessidade de uma nova maneira de se trabalhar o atendimento à população, o design de interiores, mostra-se o elemento capaz de otimizar a utilização dos ambientes. Segundo Oliveira (web, 2008) o design de interiores surgiu com a necessidade do desenvolvimento de espaços cada vez mais detalhados e personalizados, deste modo o profissional precisa estar capacitado para lidar com os avanços tecnológicos dos equipamentos e materiais, utilizando-se destes conhecimentos para projetar os ambientes.

Gubert (2011) aponta que no desenvolvimento de projetos no design de interiores é fundamental considerar a relação Homem/Espaço, levando-se em conta o perfil dos usuários, seus aspectos psicológicos, culturais e sociais, adequação econômica, além do espaço físico disponível, tais como suas dimensões, funções, elementos arquitetônicos, revestimentos, pontos elétricos, pontos hidráulicos, entre outros. Coutinho (2013) complementa afirmando que ao se referir a projetos de interiores, devem ser levantadas questões essenciais para a concepção do projeto, tais como funcionalidade, estética, conforto e sustentabilidade.

Levando-se em consideração as questões essenciais apontadas por Coutinho, a utilização das diretrizes da ergonomia é indispensável para um projeto de interiores adequado, uma vez que permite o desenvolvimento de ambientes mais eficientes e eficazes, gerando conforto aos usuários e otimizando as atividades desenvolvidas. A abordagem ergonômica é um elemento base para o desenvolvimento de projetos, e para uma utilização eficaz, é necessário levar em consideração alguns aspectos, são eles: o conforto ambiental, que engloba o conforto lumínico, térmico, acústico; a percepção ambiental, que leva em consideração os aspectos cognitivos na interação dos indivíduos com o objeto/ambiente; a antropometria, que 
considera a acessibilidade e os dimensionamentos humanos adequados; e a adequação dos materiais, que envolve a escolha adequada de revestimentos e acabamentos (VILLAROUCO et. al., 2016 apud VILLAROUCO, 2002).

Direcionando o estudo do design de interiores para o desenvolvimento de ambientes de saúde, estes são estruturas complexas, derivadas de uma combinação de forma e função, no qual a maioria dos projetos priorizam a função em relação a estética, uma vez que o layout afeta diretamente na eficiência dos procedimentos realizados. Entretanto estudos apontam que a estética dos ambientes possui efeito na recuperação dos pacientes, uma vez que define o humor e a maneira que as pessoas (pacientes, funcionários e visitantes) experimentam o ambiente, podendo fazer com que os indivíduos se sintam bem, o que consequentemente melhora o processo de cura e os procedimentos médicos realizados. Portanto, a tendência atual na elaboração de ambientes de saúde consiste em espaços que proporcionem apoio emocional e eficiência no funcionamento (CAVALCANTE, web, 2016).

Percebe-se a relevância da utilização do Design de Interiores no desenvolvimento de um ambiente destinado a atendimentos médicos, uma vez que este possibilita a otimização dos procedimentos realizados e auxilia no bem-estar dos pacientes.

\subsection{Ambientes Itinerantes de Saúde no Brasil}

Os ambientes itinerantes de saúde, possuem o objetivo de levar assistência médica a população mais carente, com dificuldade de acesso aos programas públicos convencionais e incentivar a participação em campanhas de cunho social.

Neste seguimento de projetos itinerantes, é pertinente citar alguns dos modelos de saúde existente, tal como o projeto "Consultório Itinerante", que é um programa do Ministério da Saúde em parceria com o Ministério da Educação e Hospitais Universitários Federais, que dispõe de caminhões e contêineres adaptados com consultórios completos, e possui o intuito de proporcionar aos estudantes de escolas públicas atendimentos oftalmológicos e odontológicos. Pretendendo alcançar alunos de escolas públicas de vinte Estados brasileiros, identificando problemas da visão e garantindo a saúde bucal de crianças e adolescentes (FARIAS, 2013, web; EBSERH, 2016?, web).

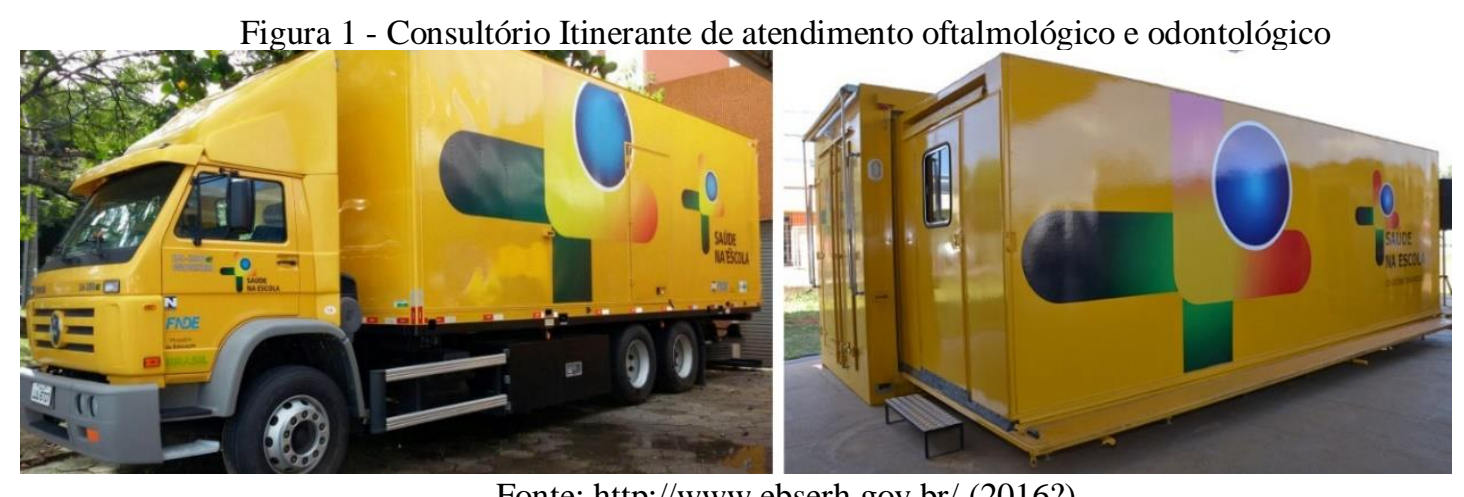

Fonte: http://www.ebserh.gov.br/ (2016?)

Nas pesquisas realizadas, constatou-se que uma parcela considerável dos programas de saúde itinerante existentes, são destinados a saúde da mulher, no qual pode-se destacar o "Mama Móvel", que consiste em uma carreta adaptada para a realização de exames de 


\section{GAMPI}

mamografia, contando com tecnologias avançadas para a detecção do câncer de mama, onde os exames são oferecidos gratuitamente (PREFEITURA DE SANTA VITÓRIA, 2017, web).

Outro programa destinado a saúde da mulher, é a unidade móvel "Mulher com Mais Saúde" do Estado de Goiás, que disponibiliza exames de prevenção de câncer de mama, do colo do útero e ultrassonografia a população, a unidade de saúde é adaptada em uma carreta e possui capacidade de realizar mensalmente, mil exames de mamografia, mil exames de papanicolau e mil exames de ultrassonografia (GOIÁS AGORA, 2015, web).

As unidades móveis de saúde da mulher, "Mama Móvel" e "Mulher com Mais Saúde", podem ser visualizadas, respectivamente, na imagem abaixo:

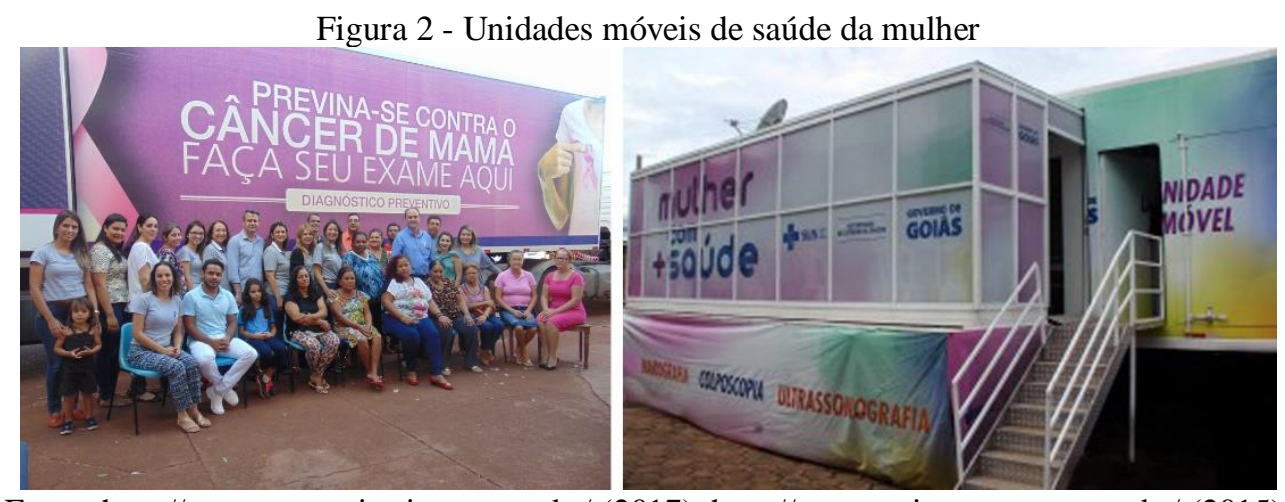

Fonte: http://www.santavitoria.mg.gov.br/ (2017); http://www.goiasagora.go.gov.br/ (2015).

Estes programas apresentados, demonstram que a utilização de espaços itinerantes se mostra eficiente e de grande valia para a população, e é uma possibilidade a ser considerada no desenvolvimento de um ambiente de saúde para a cidade de Joinville, que possui uma extensão territorial e quantidade populacional acima do suportado pelas unidades existentes. É relevante ressaltar que a maioria dos sistemas itinerantes de saúde existentes consistem em ambientes efêmeros, ou seja, são de caráter temporário, o que não seria o caso do ambiente proposto neste artigo, uma vez que ele faria parte permanentemente dos serviços oferecidos pelo SUS.

\section{Procedimentos Metodológicos}

A investigação para a proposta de uma nova alternativa de serviço público na área da saúde, caracteriza-se como teórica, no qual por meio de uma pesquisa bibliográfica, valendose de artigos científicos, dados do governo, sites e jornais, levantou-se informações sobre os seguintes temas centrais: sistema único de saúde brasileiro, saúde pública em Santa Catarina e em Joinville, design de interiores e ambientes itinerantes de saúde. Este procedimento metodológico baseia-se na metodologia elaborada por Löbach (2001), que consiste em um método de processo de design, que para o autor é um processo criativo que busca a solução de problemas. Este método é dividido em quatro fases distintas, que podem se entrelaçar, com avanços e retrocessos, e na fase da pesquisa apresentada neste artigo, será abordado a Fase de Preparação, no qual considera-se o problema como um todo, determinando-o claramente por meio de coleta e análise de informações pertinentes ao projeto. Utilizou-se também, de observação direta dos serviços públicos de saúde, para que fosse possível identificar o seu funcionamento e apontar possíveis sugestões de melhoria. 


\section{Sistema Móvel de Saúde}

Com as análises realizadas, por meio de pesquisas e observações, pode-se sintetizar as defasagens do sistema de saúde público Joinvillense, focando principalmente nos Prontos Atendimentos e nos Postos de Saúde, como as seguintes:

- Superlotação nos PA's, acarretando em demora no atendimento;

- Vagas limitadas de consultas nos Postos de Saúde, resultando em filas antes mesmo do horário de funcionamento das unidades básicas de saúde;

- Vagas limitadas para marcar exames;

- Demora excessiva para algumas consultas especializadas e procedimentos mais complexos;

- Poucos profissionais da saúde disponíveis;

- Somente 3 Prontos Atendimentos em uma cidade de aproximadamente 570 mil habitantes, gerando superlotações e deslocamentos excessivos de alguns usuários;

- Falta de medicamento nos Postos de Saúde e nos PA's.

Ao analisar esta situação, questiona-se como o design de interiores pode auxiliar no desenvolvimento de um ambiente destinado a atendimentos públicos de saúde, que otimize e facilite o acesso da população a um direito básico, que é a saúde.

Percebeu-se então, que o ponto de partida para uma proposta diferenciada seria focar na redução dos deslocamentos dos pacientes, levando atendimento médico a população mais distante dos PAs e UBs. Atualmente a cidade conta apenas com modelos fixos de estabelecimentos de saúde, mutirões de saúde móveis esporádicos e o SAMU, para atendimento móvel de emergência.

Neste cenário, e com o objetivo de reduzir os deslocamentos e as superlotações do sistema público de saúde, este projeto possui como proposta o desenvolvimento de postos móveis de saúde, no qual o design de interiores será empregado na adaptação de espaços destinados primariamente para transportes, em espaços para atendimentos médicos, que irão auxiliar a suprir a demanda na área da saúde de Joinville, de modo eficiente e sustentável.

Ao começar a pensar no sistema itinerante de atendimento médico, pontuou-se possíveis espaços móveis que poderiam ser adaptados para a finalidade proposta, tais como ônibus, trailers, caminhões e contêineres. Ao analisar as alternativas percebeu-se que os contêineres disponibilizam mais possibilidades de layouts e de distribuição das esferas de atendimento (recepção, sala de espera e consultório), uma vez que os contêineres já são utilizados para construir residências e afins, além de serem uma matéria prima resistente e com custo reduzido, já a adaptação de ônibus tornaria mais rápido o processo de deslocamento pela cidade, e necessitaria de menos modificações em sua estrutura. Portanto, uma definição precisa, só será realizada posteriormente, em um estudo mais aprofundados das possibilidades, podendo até mesmo ser utilizado mais de uma opção de espaço móvel para compor o sistema itinerante de saúde.

Independentemente do espaço definido, para projetar o ambiente de saúde, alguns pontos importantes devem ser levados em consideração, tais como a verificação da necessidade de isolamentos térmicos e acústicos, a definição da iluminação adequada, as cores que serão utilizadas, os materiais e revestimentos, além dos layouts e dimensionamentos ergonômicos e acessíveis, que facilitem as tarefas desenvolvidas. Todos estes fatores devem ser definidos e especificados conforme estudos, que apontem uma melhor adequação ao projeto.

Os postos móveis de saúde, serão projetados conforme especialidades distintas, como por exemplo, posto pediátrico, obstétrico, de atendimento geral, entre outros, conforme maiores 6o GAMPI Plural, 2017, Joinville, SC. 
demandas verificadas nos levantamentos de dados. Este sistema móvel de saúde possuirá itinerário definido junto a prefeitura de Joinville, no qual cada um permanecerá em diferentes localidades, por aproximadamente uma semana, podendo se prolongar dependendo da demanda da região.

O itinerário, cronograma e tempo de permanência de cada posto estará disponibilizado no site da prefeitura e em um aplicativo de celular, que apresentará a localização atual de cada posto móvel, além das próximas regiões em que se estabelecerá.

Cada posto móvel contará com profissionais capacitados para a sua finalidade, medicamentos e instrumentos necessários, além de convênios com farmácias da cidade, o que facilitará o atendimento caso a medicação necessária para o tratamento não estiver disponível.

$\mathrm{O}$ design de interiores mostra-se, portanto, como um elemento significativo para o desenvolvimento desta proposta, norteando toda a elaboração dos ambientes e seus futuros detalhamentos em um trabalho de conclusão de curso.

\section{Considerações Finais}

Ao observar o sistema público de saúde da cidade de Joinville, percebeu-se que este sofre com certas defasagens em relação aos serviços oferecidos, e ao focar nos serviços de baixa e média complexidade, a cidade apresenta somente 3 Prontos Atendimentos e 55 Unidades Básicas de Saúde e estes se mostram insuficientes para atender toda a população. Neste sentido, o foco da proposta deste artigo foi apresentar um estudo que possibilitasse informações para o desenvolvimento de postos móveis de saúde, que se implantado irá contribuir com a redução dos deslocamentos da população em busca de atendimento médico e das superlotações, que se apresentam como obstáculos consideráveis no acesso aos serviços públicos de saúde, melhorando assim, a qualidade da saúde pública da cidade.

Apontou-se, deste modo, a possibilidade de um ambiente móvel de saúde, no qual as diretrizes do design de interiores serão empregadas na elaboração de espaços que se adequem as necessidades dos atendimentos médicos e dos usuários, otimizando e facilitando as atividades realizadas, de modo funcional, confortável e agradável.

Este artigo contribuiu para uma melhor compreensão do tema de estudo, uma vez que possibilitou o levantamento das principais defasagens nos serviços públicos de saúde, demonstrando a necessidade do desenvolvimento de uma nova abordagem no sistema de saúde. Além de apontar as primeiras diretrizes do desenvolvimento de um serviço móvel de saúde, servindo como um estudo preliminar para análises futuras mais aprofundadas e a elaboração detalhada de tais ambientes.

Esta investigação teve, portanto, como propósito buscar subsídios que permitam ao final deste estudo,o desenvolvimento de um referencial teórico para o projeto de conclusão de curso (TCC) que terá como premissa auxiliar os serviços públicos de saúde da cidade de Joinville a diminuir a demanda existente e possivelmente colaborar com a melhoria da qualidade de vida da população, demonstrando que o design de interiores pode além de criar ambientes que auxiliam no bem estar das pessoas, também otimizar processos. 


\section{Referências}

ALVES, F. Saiba as diferenças entre postos de saúde, UPAs e hospitais. In: NDonline, 2014. (https://ndonline.com.br/florianopolis/noticias/saiba-as-diferencas-entre-postos-de-saudeupas-e-hospitais)

CAVAlCANTE, F. Design Hospitalar: Arquitetura a serviço da cura. In: Fabiana Cavalcante, 2016. (http://fabiannacavalcante.com.br/design-hospitalar/2

COUTINHO, E. C. Conceito sustentável na decoração de interiores. Revista Especialize Online IPOG, Goiânia, v.01, n 005, jul. 2013.

EBSERH. Consultórios Itinerantes. In: Brasil, 2016?. (http://www.ebserh.gov.br/web/hcuftm/consultorios-itinerantes)

FARIAS, W. Centro de Saúde/UFPB inicia programa Consultórios Itinerantes. In: Brasil, 2013. (http://www.ufpb.br/content/centro-de-sa\%C3\%BAdeufpb-inicia-programaconsult\%C3\%B3rios-itinerantes)

G1. Faltam médicos, verba e aparelhos: veja problemas da saúde em SC. In: G1, 2016. (http://g1.globo.com/sc/santa-catarina/noticia/2016/04/faltam-medicos-verba-e-aparelhosveja-problemas-da-saude-em-sc.html)

Estado perdeu 22 leitos hospitalares em 2016: Renato Igor comenta. In: G1, 2016. (http://g1.globo.com/sc/santa-catarina/bom-dia-santa-catarina/videos/v/estado-perdeu-22leitos-hospitalares-em-2016-renato-igor-comenta/5529380/)

Situação grave na saúde pública de Joinville. In: G1, 2016. (http://g1.globo.com/sc/santa-catarina/jornal-do-almoco/videos/v/situacao-grave-na-saudepublica-de-joinville/5458753/)

GOIÁS AGORA. Unidade Móvel da Mulher será lançado nesta quarta-feita. In: Goiás Agora, 2015. (http://www.goiasagora.go.gov.br/unidade-movel-da-mulher-sera-lancadanesta-quarta-feira)

GUBERT, M. L. Design de Interiores: a padronagem como elemento compositivo no ambiente contemporâneo. Porto Alegre: Dissertação (Especialização em Design) Universidade Federal do Rio Grande do Sul, 2011.

IBGE. Santa Catarina. In: Instituto Brasileiro de Geografia e Estatística - IBGE, 2016. (http://cidades.ibge.gov.br/xtras/perfil.php?codmun=420910)

MIRA, T. M. Filas na saúde pública em Joinville somam 109 mil pessoas. In: NDonline, 2014. (https://ndonline.com.br/joinville/noticias/filas-na-saude-publica-em-joinville-somam109-mil-pessoas)

MV. Alguns dados sobre a saúde pública em que você precisa ficar de olho. In: MV, 2016. (http://www.mv.com.br/pt/blog/alguns-dados-sobre-a-saude-publica-brasileira-em-que-voce- 


\section{plural $^{\text {GAT }}$ \\ precisa-ficar-de-olho)}

OLIVEIRA, P. Tudo que você precisa saber sobre Design de Interiores e Ambientes. In: Design: Ações e Críticas, 2008. (https://paulooliveira.wordpress.com/2008/06/30/tudo-quevoce-precisa-saber-sobre-design-de-interiores-e-ambientes/2

PAIM, J.; TRAVASSOS C.; ALMEIDA C.; BAHIA L.; MACINKO, J. O sistema de saúde brasileiro: história, avanços e desafios. Saúde no Brasil, n. ${ }^{\circ}$ 0, p. 11-27, maio 2011.

PEREIRA, M. Crise no Sistema Único de Saúde em Santa Catarina se agrava a cada dia. In: DC, 2016. (http://dc.clicrbs.com.br/sc/colunistas/moacir-pereira/noticia/2016/02/crise-nosistema-unico-de-saude-em-santa-catarina-se-agrava-a-cada-dia-4982504.html)

PREFEITURA SANTA VITÓRIA. Exames de mamografia foram realizados em Santa Vitória através de parceria da Secretaria de Saúde com a Carreta Móvel do Hospital do Câncer de Patrocínio. In: Prefeitura Santa Vitória, 2017.

(http://www.santavitoria.mg.gov.br/2017/06/exames-de-mamografia-foram-realizados-emsanta-vitoria-atraves-de-parceria-da-secretaria-de-saude-com-a-carreta-movel-do-hospital-docancer-de-patrocinio/)

RIOS, M. Brasil no ranking de países que investem em saúde. In: Investimentos e Notícias, 2015. (http://www.investimentosenoticias.com.br/noticias/saude/brasil-no-ranking-de-paisesque-investem-em-saude)

ROSSI, M. Saúde pública no Brasil ainda sofre com recursos insuficientes. In: Câmera dos Deputados, 2015. (http://www2.camara.leg.br/camaranoticias/noticias/SAUDE/480185SAUDE-PUBLICA-NO-BRASIL-AINDA-SOFRE-COM-RECURSOSINSUFICIENTES.html)

SANTOS, I.S.; SANTOS, M.A.B.; BORGES, D.C.L. Mix público-privado no sistema de saúde brasileiro: realidade e futuro do SUS. A saúde no Brasil em 2030 - prospecção estratégica do sistema de saúde brasileiro: estrutura do financiamento e do gasto setorial, $n .^{\circ} 4$, p. 73-131, 2013.

SECRETARIA DE PLANEJAMENTO URBANO E DESENVOLVIMENTO SUSTENTÁVEL. Joinville: Cidade em Dados 2017. Joinville: Prefeitura Municipal, 2017.

SOUZA, R.R. O Sistema Público de Saúde Brasileiro. Brasília: Ministério da Saúde, 2002.

VILLAROUCO, V. et al. Cenário da produção científica brasileira sobre ergonomia do ambiente construído (2005 - 2015). Recife: Eneac, 2016. 